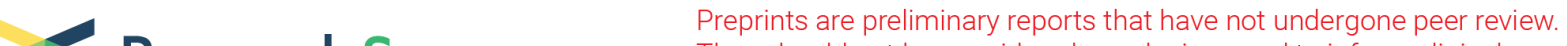 Research Square They should not be considered conclusive, used to inform clinical practice, or referenced by the media as validated information.
}

\section{Can a Complex Vocational Rehabilitation Intervention Be Delivered With Fidelity? Fidelity Assessment in the Fresh Feasibility Trial}

Jain Anne Holmes ( $\nabla$ jain.holmes@nottingham.ac.uk)

The University of Nottingham, Faculty of Medicine and Health Sciences, Division of Rehabilitation, Ageing and Wellbeing, B Floor, Medical School, Queen's Medical Centre, Nottingham, NG7 2UH, England https://orcid.org/0000-0003-2465-102X

Joanna Clare Fletcher-Smith

University of Nottingham School of Medicine

Jose Antionio Merchán-Baeza

Universitat de Vic - Universitat Central de Catalunya

Julie Phillips

University of Nottingham School of Medicine

Kathryn Radford

University of Nottingham School of Medicine

Research

Keywords: Implementation, complex intervention, fidelity, adherence, moderating factors, vocational rehabilitation, brain injury, mixed methods

Posted Date: September 10th, 2020

DOI: https://doi.org/10.21203/rs.3.rs-72353/v1

License: (c) (1) This work is licensed under a Creative Commons Attribution 4.0 International License. Read Full License 


\section{Abstract}

\section{Background:}

Determining whether complex rehabilitation interventions are delivered with fidelity is important as differences can occur between sites, therapists delivering the intervention and over time; threatening trial outcomes and increasing the risk of Type II and Type III errors. Aims: to (1) evaluate implementation fidelity of vocational rehabilitation delivered in FRESH, a multi-centre feasibility randomised controlled trial; and (2) understand factors affecting delivery.

\section{Methods:}

Mixed methods evaluation. Fidelity was measured quantitatively using intervention case report forms, fidelity checklists and clinical records. Qualitative data from mentoring records, interviews with the intervention therapists, participants and their employers and NHS staff at each site explored moderators of implementation fidelity. The quantitative and qualitative data informed data collection tools and analysis. Data were examined against a logic model and benchmarked against an earlier cohort study.

\section{Results:}

Analysis of 38 clinical records (one per participant), 699 content CRFs (42-248 per therapist) and 12 fidelity checklists suggest intervention was delivered as intended. The core intervention process was followed in each case despite therapist variation. Qualitative data from clinical records, fidelity checklists, 183 mentoring records and 38 interviews (4 therapists, 15 trial participants, 6 employers and $13 \mathrm{NHS}$ staff) explained factors affecting intervention fidelity. Fidelity moderators were similar across sites. Facilitators included therapists' community rehabilitation experience, expert mentoring, and ability to individually tailor intervention. Barriers involved a lack of access to NHS systems no backfill and limited line-manager support. Factors that both helped or hindered intervention delivery were effective communication with participants, intervention acceptability, participants' changing needs and interagency working. Different fidelity measures answered different questions. Fidelity checklists determined whether intervention processes were followed and explained moderators. Interviews provided insights into acceptability. Adherence was determined by content forms. Mentoring records described implementation barriers and how they were overcome.

\section{Conclusions:}

Mixed methods fidelity assessments enable trialists to identify factors likely to affect intervention fidelity in a definitive trial and longer-term clinical implementation. Mentoring provided insight into engagement and fidelity deviations that could be addressed in real-time, facilitating fidelity and offering a window on trial processes

Trial registration: ISRCTN Registry, ISRCTN38581822 (Registered:

02/01/2014) (https://doi.org/10.1186/ISRCTN38581822) 


\section{Contributions To The Literature}

- The 'Conceptual Framework of Implementation Fidelity' guides data collection and analysis of fidelity in a feasibility trial.

- The use of a benchmark provided a measure of the degree to which OTs adhered to the intervention as described in the logic model.

- Whilst multiple measurement methods provide fidelity results at the end of a study, mentoring provides a useful method for monitoring of fidelity throughout.

\section{Background}

Every year in the UK, around 160,000 people sustain a traumatic brain injury (TBI) (1) defined as an injury to the brain caused by a trauma to the head (head injury) (2). Causes include road traffic accidents, assaults, falls and accidents (1). TBI can result in impaired mobility, cognition and social skills, problems with mood and managing emotions $(3,4)$ and reduced quality of life $(5,6)$. Such factors can affect the person's ability to regain functional independence and return to work (7). Return to work is an important rehabilitation goal for many survivors of TBI (8). Employment provides economic security, but supports physical, psychological and social health (9). However, vocational rehabilitation (VR) services to support people recovering from brain injury are rare, and data on their effectiveness is limited $(9,10)$.

The Facilitating Return to work through Early Specialist Health-based interventions (FRESH) study (11) was funded by the National Institute for Health Research (NIHR) Health Technology Assessment (HTA) Programme to test the feasibility of conducting a future study to determine whether early VR delivered by occupational therapists (OTs) to support people with TBI in returning to work is effective and costeffective. It involved a multi-centre, feasibility, parallel group randomised controlled trial with feasibility economic evaluation.

An important component of FRESH was an embedded mixed-methods process evaluation to provide context to the study findings and identify implementation issues for consideration in a definitive trial. The process evaluation involved a comprehensive assessment of intervention fidelity, which is acknowledged as key to understanding how intervention adaptations made during the trial relate to participant and trial outcomes (12) or how they can be used to optimise the intervention before embarking on a fully powered trial (13).

Intervention fidelity is particularly important in trials where a complex intervention, such as VR, is being delivered, because of the potential differences across sites, providers and over time (14-16). It is important to understand whether variable intervention effects could result from differences in intervention fidelity (17). Ensuring clinicians are adequately prepared to implement the intervention and then monitoring fidelity throughout is important to optimise patient outcomes $(15,18)$. 
Moving directly from a feasibility study to a large-scale definitive trial without considering implementation issues could perpetuate poor patient outcomes $(19,20)$, prevent trialists from improving research design $(21,22)$ and halt scientific discovery of interventions that have been wrongly determined ineffective (23). Trialists who do not measure fidelity are at risk of ignoring type III errors, whereby outcomes are attributed erroneously to treatment effectiveness (24).

In FRESH the OTs were trained face-to-face, supported by a manual informed by a logic model describing the intervention components and processes (Additional file 3). The OTs were also supported by a mentor experienced in vocational rehabilitation for the duration of intervention delivery $(25,26)$. The purpose of which was to monitor fidelity $(14)(27,28)$ and enhance therapists' adherence $(29)$.

The Conceptual Framework for Implementation Fidelity (CFIF) combined a number of theoretical concepts of fidelity $(30)$. CFIF $(11,31,32)$ helps identify factors affecting fidelity and intervention delivery (implementation) in clinical trials. CFIF consolidates fidelity $(24,27,33-39)$ recognising two accepted domains: 'adherence' (content, coverage, frequency and duration (also recognised as dose) of intervention); and 'potential moderating factors' (participant responsiveness, intervention complexity, strategies to facilitate implementation, quality of delivery, recruitment, and context).

The aim of this study was to systematically evaluate implementation fidelity and factors influencing fidelity of a complex TBI VR intervention delivered by occupational therapists in the FRESH feasibility trial.

\section{Methods}

In the FRESH trial (11), 78 traumatic brain injured participants were randomly allocated to the VR intervention in addition to their usual NHS rehabilitation (intervention group) or usual NHS rehabilitation alone (control group) in three regions (the North West, London, and Yorkshire) of England over 12 months. The primary outcome was participants' work status, defined as a minimum of an hour per week of paid or unpaid work, analysed at 12-months using an intention-to-treat approach.

Implementation fidelity was measured as part of an embedded process evaluation. Data collection was longitudinal (Additional file 1). Quantitative process data consisted of content of treatment records, fidelity checklists, mentoring records and clinical occupational therapy records). Qualitative data collection methods included interviews, therapy and mentoring records. Both types of data enabled evaluation of the intervention process implementation and its fidelity during the study as subsequently recommended by Toomey et al (2017) (40).

The Conceptual Framework for Implementation Fidelity (CFIF) (30) was used to guide both the measurement of fidelity and understand factors affecting its delivery. The CFIF structure facilitated the development of measurement tools, including a fidelity checklist $(12,41-43)$, data collection (44) and analysis (45). 
Participants included patients recruited to the FRESH feasibility randomised controlled trial (RCT) who were randomised to receive the FRESH VR intervention. Inclusion criteria were people aged 16 years or above, admitted to one of three major trauma centres for 48 hours or more, with a new TBI (within 8 weeks) and who were in paid or unpaid work or full-time education prior to injury. Full eligibility criteria in the FRESH RCT are explained elsewhere (46). Clinical records and intervention session case report forms (CRFs) were collected for every intervention participant $(n=38)$. Purposive sampling was used to identify and recruit five participants for telephone interviews from each site with a range of demographics and TBI severity who had received the intervention $(n=15)$.

The five OTs who delivered the intervention were Health and Care Professions Council registered with expertise in VR. OTs attended two days of training, plus an additional day six-months after intervention delivery commenced. This is described elsewhere $(25,26)$. Training was delivered by a team of four OTs with expertise in VR, TBI and research. Training was supplemented by an intervention manual and monthly individual mentoring by a member of the training team to support implementation during the intervention delivery period. OTs could contact their mentor for advice when they needed it.

Employer participants included line managers, human resource professionals, or occupational health professionals of patient participants in employment or teaching staff linked to participants in full-time education. A convenience sample of 15 employers were recruited (five from each site). Only employers of people with TBI (PwTBI) randomised to receive the intervention were eligible.

NHS staff participants included those staff at each site, who, in their usual role, were involved in managing, commissioning, or delivering TBI rehabilitation. A convenience sample of $15 \mathrm{NHS}$ staff were recruited (five from each site).

The VR intervention, described using the TIDieR checklist in Additional file 2 and elsewhere (47-49) was delivered to the FRESH participants by an OT (described above). The primary focus of the intervention was preventing job loss and optimising employment and education outcomes. The intervention started within eight weeks of injury and lasted up to 12 months. The logic model for the FRESH intervention is described in Additional file 3.

Ethical approval was granted by Integrated Research Approval System (REC Ref: 13/EM/0353 and the University of Nottingham Ethics Ref: D14112013 FRESH). The process for obtaining participant (patient participants, OT participants, employer participants, NHS staff participants) informed consent was in accordance with Research Ethics Committee guidance and Good Clinical Practice (50).

Data was collected about every session delivered by every OT during the FRESH intervention delivery phase between January 2014 and January 2016. A description of each data collection tool, time points for data collection, data type, which CFIF construct they related to, their purpose and data usage are shown in Table 1. 
Table 1

Data Collection Tools and Timeframes for Data Collection

\begin{tabular}{|c|c|c|c|c|c|}
\hline Tool & Timeframe & Data type & $\begin{array}{l}\text { CFIF } \\
\text { construct }\end{array}$ & Tool purpose & Data usage \\
\hline $\begin{array}{l}\text { Intervention } \\
\text { CRF }\end{array}$ & Continuous & Quantitative & Adherence & $\begin{array}{l}\text { Quantity of components } \\
\text { (10-minute units) } \\
\text { delivered per session, } \\
\text { direct participant activity } \\
\text { (face-to-face, telephone), } \\
\text { travel, indirect activity } \\
\text { (e.g. session } \\
\text { preparation) }\end{array}$ & $\begin{array}{l}\text { Triangulated } \\
\text { with clinical } \\
\text { record }\end{array}$ \\
\hline $\begin{array}{l}\text { Clinical } \\
\text { record }\end{array}$ & Continuous & $\begin{array}{l}\text { Quantitative } \\
\text { and } \\
\text { qualitative }\end{array}$ & $\begin{array}{l}\text { Adherence } \\
\text { and } \\
\text { moderating } \\
\text { factors }\end{array}$ & $\begin{array}{l}\text { Description of } \\
\text { intervention plus } \\
\text { evidence of } \\
\text { correspondence }\end{array}$ & $\begin{array}{l}\text { Triangulated } \\
\text { with } \\
\text { intervention } \\
\text { CRF }\end{array}$ \\
\hline $\begin{array}{l}\text { Fidelity } \\
\text { checklist }\end{array}$ & $\begin{array}{l}\text { Quarterly at } \\
\text { monitoring } \\
\text { visits }\end{array}$ & $\begin{array}{l}\text { Quantitative } \\
\text { and } \\
\text { qualitative }\end{array}$ & $\begin{array}{l}\text { Adherence } \\
\text { and } \\
\text { moderating } \\
\text { factors }\end{array}$ & $\begin{array}{l}\text { Oversight per OT, extent } \\
\text { of components delivered } \\
\text { (always to never), } \\
\text { moderating factors } \\
\text { affecting delivery. } \\
\text { Advise OTs }\end{array}$ & $\begin{array}{l}\text { Triangulated } \\
\text { with } \\
\text { intervention } \\
\text { CRF, clinical } \\
\text { record, } \\
\text { mentoring } \\
\text { CRF. }\end{array}$ \\
\hline $\begin{array}{l}\text { Mentoring } \\
\text { CRF }\end{array}$ & Monthly & Qualitative & $\begin{array}{l}\text { Adherence } \\
\text { and } \\
\text { moderating } \\
\text { factors }\end{array}$ & $\begin{array}{l}\text { Intervention summary } \\
\text { provided by each OT, } \\
\text { details factors affecting } \\
\text { delivery and potential } \\
\text { solutions }\end{array}$ & $\begin{array}{l}\text { Triangulated } \\
\text { with } \\
\text { intervention } \\
\text { CRF, clinical } \\
\text { record, } \\
\text { fidelity } \\
\text { checklist }\end{array}$ \\
\hline $\begin{array}{l}\text { Interview } \\
\text { with OTs }\end{array}$ & $\begin{array}{l}\text { Start of } \\
\text { intervention } \\
\text { delivery \& } \\
\text { End of } \\
\text { delivery }\end{array}$ & Qualitative & $\begin{array}{l}\text { Moderating } \\
\text { factors }\end{array}$ & $\begin{array}{l}\text { Addressed acceptability } \\
\text { of the intervention, the } \\
\text { factors affecting } \\
\text { delivery and solutions to } \\
\text { overcome barriers }\end{array}$ & $\begin{array}{l}\text { Triangulated } \\
\text { with mentor } \\
\text { CRF, clinical } \\
\text { record. }\end{array}$ \\
\hline $\begin{array}{l}\text { Interview } \\
\text { with } \\
\text { PWTBI, } \\
\text { their } \\
\text { employers } \\
\text { and NHS } \\
\text { staff }\end{array}$ & $\begin{array}{l}\text { End of } \\
\text { intervention } \\
\text { delivery }\end{array}$ & Qualitative & $\begin{array}{l}\text { Moderating } \\
\text { factors }\end{array}$ & $\begin{array}{l}\text { Addressed acceptability } \\
\text { of the intervention, the } \\
\text { factors affecting } \\
\text { delivery and solutions to } \\
\text { overcome barriers }\end{array}$ & $\begin{array}{l}\text { Triangulated } \\
\text { with mentor } \\
\text { CRF, clinical } \\
\text { record. }\end{array}$ \\
\hline
\end{tabular}

Key: Continuous = OT completed the CRF and clinical record after each session. CFIF Adherence includes intervention content, coverage, frequency and duration of intervention; CFIF Moderating factors includes participant responsiveness, intervention complexity, strategies to facilitate implementation, quality of delivery, recruitment, and context.

Quantitative adherence data (content, coverage, frequency and duration of intervention); and qualitative data explaining moderators of fidelity (participant responsiveness, intervention complexity, strategies to 
facilitate implementation, quality of delivery, recruitment, and context) were extracted from the tools and compared, through triangulation, for data verification and to identify missing data by an independent researcher. Each intervention session was recorded on an intervention CRF that was modified from one initially developed by Phillips et al (48) plus clinical records following the OTs' own local policies and procedures.

A fidelity visit checklist (Additional file 4) for use by an expert rater, was developed to measure whether OTs adhered to the core intervention processes. It was based on an observational checklist designed by Hasson et al (44) informed by the theoretical constructs of CFIF. As recommended by others $(17,27)$, the checklist comprised the intervention components and core processes extracted from the FRESH intervention logic model (Additional file 3). Fidelity to each was rated on a 5-point ordinal scale as delivered: 'always', 'often', 'sometimes', 'seldom' or 'never' (where 'always' scored 1 and 'never' scored 5). Factors that affected the delivery of the intervention were recorded alongside. Guidance notes helped assignment of ratings.

Each OT received four fidelity check visits by a post-doctoral research OT (JP) who was also a trial mentor. OTs provided anonymised copies of clinical notes and intervention CRFs prior to a visit. The researcher and OT met and discussed the intervention delivered to participants. The researcher systematically rated each component on the checklist. Following the visit, data were recorded on an Excel document by a member of the study team. Fidelity checklists were discussed between the mentoring team and were used to identify non-adherence to intervention delivery and then translated into topics for skill-building during ongoing mentor sessions (51).

Content of each monthly mentoring session was recorded on a mentoring CRF by the mentor, additional mentor support by email and phone calls were also collected.

Interviews with OTs were conducted early after training and later to capture the OTs varying experience of delivering the intervention. PWTBI and their employers and NHS staff were interviewed at the end of the intervention. Interviews followed a topic guide informed by the theoretical constructs of $\operatorname{CFIF}(30,44)$ to capture qualitative data on factors affecting implementation fidelity. Interviews took place by telephone and lasted approximately 45 minutes. They were digitally recorded, fully transcribed, cleaned and the data was uploaded to SQR Nvivo software for analysis.

\section{Data Analyses}

All constructs of fidelity, based on the CFIF, were measured to avoid gaps in reporting and data were compared to:

- the expected content,

- the proportion of components,

- required processes, 
- required frequency and intervention duration (dose).

The intervention logic model and a benchmark were used to guide data analysis and interpretation. There is no specific guidance to answer, "How much variation is allowed in fidelity measurement?" but Durlak and DuPre (52) (2008) indicated, in their meta-analysis of 542 interventions between 1976 and 2006, that outcomes were effective when interventions were delivered with $60-80 \%$ fidelity. They advised researchers not to expect $100 \%$ fidelity and recommended that the variation in fidelity across sites should be reported rather than only presented as a mean, because this can mask expected variation.

Carroll et al (30) suggest using a benchmark against which to measure fidelity, as this adds to understanding the quality of the intervention delivered. The benchmark used for this comparison was Phillips' (47) description of an early VR intervention for PwTBI, which informed the development of the FRESH intervention. Quantitative data about the proportion of components delivered by the OTs were compared to the same data provided by Phillips (2013) to illustrate how closely they matched.

Fidelity checklists were analysed using the 5-point scale after each monitoring visit. Data obtained from clinical records and intervention CRFs were triangulated to identify variations in fidelity and disagreement between data sources. Where there was disagreement e.g. in the recording of a session, the clinical record was considered more likely to represent what had occurred because therapists were more familiar with this form of documentation than the intervention CRF. Descriptive statistics were used to describe the quantity and content of the intervention delivered.

Intervention content was analysed by comparing each CRF with the description of the intervention session in the clinical records. The proportion of time spent on each intervention component was calculated from the CRF. Duplicated data were removed from the analysis and missing data were recorded.

The frequency and duration of the intervention was calculated using the dates recorded in the CRFs and clinical records. Total time spent in direct contact and indirect contact with patients was taken from the content proformas. Data from the CRF and clinical records were compared to these timeframes.

Text describing factors moderating implementation fidelity (participant responsiveness, intervention complexity, facilitation strategies and quality of delivery) were extracted and triangulated across multiple records (fidelity visit checklists, clinical records, mentoring CRFs and interviews). Interview transcripts were analysed by at least two researchers using the framework method (53).

\section{Results}

Quantitative data from intervention CRFs were available for 38 PwTBI participating in the FRESH trial. Using the Glasgow coma scale (GCS) (54) to indicate TBI severity, approximately $50 \%(n=19)$ had a mild TBI, a mean age of 40.4 years (range $16-62), 87 \%(n=33)$ were male, and $71 \%(n=27)$ were in full time work prior to injury. 
Of the 38,15 consented to interview, had a mean age of 39.4 years (range $25-61), 80 \%(n=12)$ were male, six had a severe TBI, four a moderate TBI and five a mild TBI. Just over half $(n=7)$ were injured through falling, five from road traffic collisions, two from assaults and one was unsure. Six had other rehabilitation being delivered and five had occupational health services involved. Whilst all participants consented to the OT communicating with their employer, only seven consented to a workplace visit. Participants' job roles included electrician, abattoir worker, carer, rigger, restaurant waiter, teacher, business owner, administrator, IT, warehouse worker, estates manager and doctor.

Five OTs (four women) were recruited with a mean age of 39.2 years (range 34 to 47 years). OTs were qualified a mean of 11.4 years (range 12 to 15 years). Two qualified in the UK and three overseas (South Africa, New Zealand and Australia). One held a higher degree in VR. All had experience in the National Health Service (NHS) and with people with neurological conditions (mean 9.7 years, range 3-15 years). Two OTs worked for the NHS (community and acute), two were private practitioners. One OT left the trial. Two OTs were based in one site, the other two sites had one OT each.

Of the 15 TBI participants, 13 consented to their employer being contacted for interview, one was selfemployed and one declined. Six employers consented and were interviewed. Four were line managers of the patient participant, one was a human resources manager and one an occupational health provider. They represented small, medium, and large employers. Two were third-sector organisations, two education facilities, one an NHS Trust and one a restaurant.

Thirteen NHS staff from four organisations (Community NHS Trusts, Acute NHS Trusts, NHS England, and a Clinical Commissioning Group) with varying roles (including research and development, strategic clinical network manager, commissioner, community occupational therapist, lead occupational therapist, clinical services manager, and a local clinical principal investigator) consented and were interviewed.

Thirty-eight sets (one per trial participant) of clinical notes, 699 (42-248 per therapist) intervention CRFs and 12 fidelity visit checklists (one per OT over three visits) were obtained. Qualitative data was extracted from 38 sets of clinical notes, 12 fidelity visit checklists, 183 mentoring CRFs and 38 (four trial OTs, 15 PwTBI, six employers, 13 NHS staff) interview transcripts. It was planned that 16 fidelity checklists would be collected. However, it was not possible to schedule the planned four visits per OT due to busy workloads.

Triangulation of data identified missing data from clinical notes and CRFs, letters that were not recorded on the CRF; intervention sessions recorded on the CRFs that were not recorded in the clinical records; and missing intervention session dates.

Table 2 combines all the quantitative data sources (Intervention CRFs, clinical records and fidelity checklists) and illustrates whether each OT delivered the intervention with fidelity according to the adherence constructs of CFIF and indicates which type of moderating factor affected the delivery of the intervention. Overall, OTs delivered the FRESH VR with fidelity. The Fidelity Checklist which suggested the 
intervention was delivered as intended with core processes almost 'always' or 'often' followed by all therapists.

Table 2: Fidelity of FRESH intervention and identified moderating factors

\begin{tabular}{|c|c|c|c|c|c|c|c|c|}
\hline \multirow{2}{*}{\multicolumn{3}{|c|}{ Adherence }} & \multicolumn{4}{|c|}{ OTs } & \multirow[t]{2}{*}{ Moderating Factors } & \multirow{2}{*}{$\begin{array}{l}\text { Fidelity } \\
\text { Assessment }\end{array}$} \\
\hline & & & $\begin{array}{l}\text { OT } \\
\mathrm{A}\end{array}$ & $\begin{array}{l}\text { OT } \\
\text { B }\end{array}$ & $\begin{array}{l}\text { OT } \\
\mathrm{C}\end{array}$ & $\begin{array}{l}\text { OT } \\
\text { D }\end{array}$ & & \\
\hline \multicolumn{3}{|c|}{ Coverage } & $\checkmark$ & $\checkmark$ & $\checkmark$ & $\checkmark$ & $\begin{array}{l}\text { Participant responsiveness, } \\
\text { intervention complexity. }\end{array}$ & $\begin{array}{l}\text { Fidelity met in all } \\
\text { cases. }\end{array}$ \\
\hline \multicolumn{3}{|c|}{ Content } & $\checkmark$ & $\checkmark$ & $\checkmark$ & $\checkmark$ & $\begin{array}{lr}\text { Participant } & \text { responsiveness, } \\
\text { facilitation } & \text { strategies, } \\
\text { intervention } & \text { complexity and } \\
\text { context. } & \end{array}$ & $\begin{array}{l}\text { Fidelity met in all } \\
\text { cases. }\end{array}$ \\
\hline \multicolumn{3}{|c|}{ Duration } & $V^{* 1}$ & $\checkmark^{* 1}$ & $\sqrt{ }^{* 1}$ & $V^{* 1}$ & 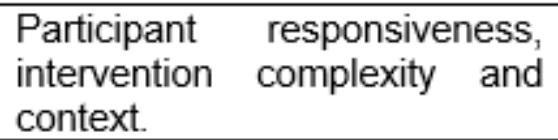 & $\begin{array}{l}\text { Fidelity met in } \\
\text { most cases. }\end{array}$ \\
\hline \multirow{4}{*}{ 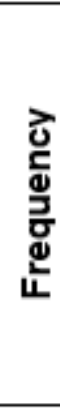 } & 1 & $\begin{array}{l}\leq 10 \\
\text { days }\end{array}$ & $\sqrt{ } * 3$ & $\checkmark^{* 1}$ & $\sqrt{ } * 3$ & $* x$ & $\begin{array}{l}\text { Participant responsiveness, } \\
\text { intervention complexity. }\end{array}$ & $\begin{array}{l}\text { Fidelity met in } \\
\text { most cases. }\end{array}$ \\
\hline & 2 & $\begin{array}{l}1-8 \\
\text { wks. }\end{array}$ & $\checkmark$ & $\checkmark$ & $\checkmark$ & $\checkmark$ & $\begin{array}{l}\text { Facilitation strategies and } \\
\text { context. }\end{array}$ & $\begin{array}{l}\text { Fidelity met in all } \\
\text { cases. }\end{array}$ \\
\hline & 3 & $\begin{array}{l}\leq 8 \\
\text { wks. }\end{array}$ & $\checkmark$ & $\checkmark$ & $\checkmark$ & $\checkmark$ & $\begin{array}{l}\text { Intervention complexity and } \\
\text { context. }\end{array}$ & $\begin{array}{l}\text { Fidelity met in all } \\
\text { cases. }\end{array}$ \\
\hline & 4 & $\begin{array}{l}\text { 4-8 } \\
\text { wks. }\end{array}$ & $\checkmark$ & $\checkmark$ & $\checkmark$ & $\checkmark$ & $\begin{array}{l}\text { Intervention complexity and } \\
\text { context. }\end{array}$ & $\begin{array}{l}\text { Fidelity met in all } \\
\text { cases. }\end{array}$ \\
\hline
\end{tabular}

However, therapists delivered the intervention differently to each other, which was influenced by caseload, participants' needs and circumstances. Because of the intervention's complexity, variation across OTs and different sites was expected. Variation was within $12 \%$ of the benchmark (Fig. 2) for most intervention components. An exception was a component (RTW) delivered 30\% more than the benchmark by one therapist (OT-D) but within what is considered acceptable (52). Mapping relevant portions of text extracted from clinical records, fidelity checklists, mentoring CRFs and interviews to the CFIF moderating factors constructs highlighted and explained what affected intervention delivery (Table 2).

Coverage refers to ensuring that sufficient proportion of the targeted population receive the entire intervention. Of the 38 PWTBI receiving the intervention, four (10.52\%) withdrew after a mean of 17.5 visits (range 6-39) combined. Reasons included: "disagreement with the therapist regarding safety to drive"; "back at work"; "retired"; "coping" and "moved away and no contact details".

Having contact with the employer was considered a core component of the intervention and OTs had contact with all employers/teachers. OTs had direct contact with 14 (37\%) employers and indirect contact (vicariously through the PwTBI) with 24 (63\%) employers. The benchmark had direct contact with $28.5 \%$ 
$(\mathrm{N}=8)$ employers, indirect contact with $55 \%(\mathrm{~N}=16)$ and no contact with $16.5 \%(\mathrm{~N}=5)$. OT-A and OT-B had direct contact with their PwTBI's employers for more than half of their caseload $(67 \%(n=6)$ and $55 \%$ $(n=4)$, respectively). OT-D had direct contact with $4(24 \%, n=17)$ employers and OT-C only had indirect contact with employers.

Overall, $60 \%$ (benchmark $70 \%$ ) of OTs' time was spent delivering the intervention and $40 \%$ (benchmark $30 \%$ ) spent in supportive activity, comparative to the benchmark (Fig. 1). The proportion of time spent in direct delivery was also similar across OTs (OT-A $=65 \%$, OT-B $=58 \%$, OT-C $=54 \%$ and OT-D $=59 \%)$.

The three intervention components most frequently delivered across OTs, in descending order, were work preparation (22\%) (benchmark 23\%), return to work (19\%) (benchmark $14 \%$, and assessment (14\%) (benchmark 15\%). Due to an adaptation to the intervention CRF from the original study by Phillips (2013), there is no comparator to 'family support'. 'Family support' did not feature as a separate component in the benchmark and was included under the heading 'current issues' (Phillips, J. 2013).

Whereas Fig. 1 illustrates the mean proportion of time delivering each component by all OTs, individual variations are shown in Fig. 2 where data are normalised with $0 \%$ representative of the benchmark. Not investigating individual differences can "hide" some important findings. For example, calculated as a mean, the fourth most frequently delivered component was "family support" but only OT-B had delivered this.

Whilst most components were delivered close to $10 \%$ variation, three components (current issues, RTW and work preparation) were delivered with greater. Moderating factors extracted from mentoring CRFs and clinical records explained this was due to tailoring the intervention to meet participants' needs. OT-D delivered more 'return to work' due to a single participant who successfully returned to work but then experienced new workplace relationship issues requiring proportionally more OT support. Proportionately, OT-C delivered more work preparation than all other OTs and the benchmark because one participant had pre-existing addiction issues and one with neuropsychological symptoms and this explained the additional preparation required for return to work. OT-B delivered more 'current issues' due to a single participant requiring additional support navigating multiple medical appointments.

Frequency and duration (dose) were recorded on the fidelity checklist as four key time points and findings indicated close adherence to the key time points but with some variation. Intervention CRFs and clinical records revealed variations in the number of direct visits with participants. Based on Phillips (2013) study, it was anticipated that participants would receive an average of 11 sessions. The frequency of visits per participant was highest in the first month and then declined in frequency. The mean number of face-toface sessions per therapist per whole caseload is shown in Table 3. 
Table 3

Number of face-to-face visits per therapist per whole caseload

\begin{tabular}{|ll|}
\hline & Mean face-to-face sessions per participant \\
\hline Benchmark & $11.2($ range $1-23)$ \\
\hline OT-A $(n=11)$ & $6.7($ range 1 to 19$)$ \\
OT-B $(n=6)$ & $9.5($ range 2 to 40$)$ \\
OT-C $(n=4)$ & $5.75($ range 2 to 13$)$ \\
OT-D $(n=17)$ & $5.00($ range 0 to 26$)$ \\
\hline Total $(n=38)$ & $6.3($ range $0-40)$ \\
\hline
\end{tabular}

OTs demonstrated fidelity to the duration of the VR intervention except each OT exceeded the 12-month duration with a single participant. Moderating factors related to participants' needs explained reasons for two OTs:

1. OT-A had a participant who returned to the same job, same employer and remained on the OT's caseload for 11 months but without receiving intervention and used the maximum 12-month allowable as a follow-up period in case any problems occurred (with job retention).

2. OT-B had a participant who did not return to work and needed referrals to 10 further services to meet trauma-related needs. Lengthy NHS waiting times meant the therapist monitored the PwTBI beyond 12 months until these services were in place.

3. OT-C had a participant who had not been in regular work prior to recruitment. Regular intervention was recorded over eight months and discharge was recorded close to 12-months, but contact was made again at the 16-month point but without clear reasons.

4. OT-D had a participant who returned to studying. Clinical records did not provide clear reasons for discharging after the 12-month point.

There was variation in the duration of intervention delivery between therapists and between participants. Nearly three months difference was measured between the participants seen for the shortest (9 days) and the longest (456 days) durations. There was no benchmark comparison for duration.

\section{Moderating Factors}

Factors affecting participant responsiveness and acceptability of the intervention varied. Regular contact with participants was required. OTs explained this was difficult in some cases, especially when people had returned to work. Some PwTBI reflected they had busy lives and found it difficult to make time for the intervention. 
Communication was affected when participants temporarily stayed out of area, moved out of area or when aphasia interfered with communication. Even when PwTBI provided permission for OTs to contact their employers about RTW, some employers did not reciprocate, which was a barrier to intervention delivery.

The majority of PWTBI interviewed reported that they found the intervention helpful in achieving goals and considered the intervention was delivered appropriately. Mentoring and clinical records indicated that some PwTBI were unhappy with the intervention, or part of it and ceased engagement but did not formally withdraw from the trial. Records also indicated that some felt the intervention was not timed appropriately because of impending surgery or where there was no intention to work in the future.

To facilitate RTW, the OTs ideally worked directly with employers and most PWTBI provided consent, indicating acceptability. Employers interviewed also had positive views of the intervention. Employers valued the OT's expertise and clear communication, which helped to gain their trust and engagement. Mentoring records revealed that not all PwTBI allowed contact with their employer, but reasons for this were not always recorded.

All OTs were enthusiastic about the intervention and its positive effect on recipients. Some OTs worried about the ethics of providing one group of people a higher intensity programme compared to the usual caseload, others found the autonomy away from usual work restrictions as liberating.

The complexity of the intervention meant that OTs were taught the principles of how to tailor the intervention. Qualitative data showed how this was accomplished by considering individual needs of the PwTBI, the employer and changing needs over time, resulting in variability in delivery. Data indicated the intervention was tailored without detracting from fidelity and OTs valued being allowed to tailor it.

Facilitation strategies included the intervention training package. Interview data indicated OTs felt prepared to deliver the intervention, and the manual was useful for some early after training whilst mentoring helped OTs develop confidence and expertise. Fidelity visits helped OTs remember and examine their fidelity to the intervention. OTs' own experience helped in overcoming complexity such as working to meet both the needs of the PwTBI and the employers. Adequate resources for example admin support, from sites helped manage the OTs' time.

Moderating factors related to context included access to NHS systems such as the IT infrastructure to support electronic transfer of referrals, using an NHS.net email account and a secure space for clinical records away from colleagues that might otherwise cause contamination. Local geography affected delivery for example, OTs in London spent more time travelling using public transport. Cooperative working between OTs and other community teams was variable dependant on pre-existing rehabilitation and the experience of the OTs involved. Geographical boundaries and availability of services affected access to specialist services required to support intervention delivery. Limited backfill of the OT's usual role and limited manager support meant OTs were occasionally pulled away from the FRESH VR intervention for example during winter pressures. 


\section{Discussion}

The multiple data sources and mixed methods showed that OTs delivered a VR intervention with fidelity to TBI participants in a randomised controlled feasibility trial. Triangulation across and between quantitative and qualitative data sources enabled a detailed and rigorous analysis of fidelity (55). This design helped identify factors that moderated intervention delivery and explain fidelity violations (deviations in process or component delivery) to be addressed before a future large-scale trial. For example, cross-referencing quantitative (intervention case report forms (CRFs)) data indicated that one OT spent more than the expected amount of time dealing with 'current issues' and qualitative sources (clinical records and mentoring CRFs) helped to explain the reasons.

The fidelity measurement methods answered different fidelity questions. Intervention CRFs, clinical records and the fidelity checklist helped determine what and how much intervention was delivered for comparison against the benchmark. Descriptions of intervention delivery in clinical records, fidelity checklists and mentoring records indicated whether intervention processes were followed and explained moderating factors.

Quarterly monitoring visits by the OT mentor to complete fidelity checklists, each required an entire day to conduct, but provided insight into factors affecting fidelity. It was also an opportunity to realign intervention fidelity by re-educating the OTs as recommended by Moore et al., (2014). For example, at one site the fidelity checklist indicated risk assessments of the home were not routinely conducted, at another it suggested interventions were not always explicitly work-focussed. This was communicated to mentors, closely monitored, and extra support provided through mentoring until everyone was satisfied the intervention was being delivered as intended.

Mentoring records provided real-time indicators to fidelity deviations and offered a window into trial processes that could be addressed during the intervention delivery period in the live trial. Mentoring also appeared to be an important facilitating mechanism for supporting intervention fidelity, which is consistent with findings reported elsewhere $(56,57)$.

While multiple data sources corroborated findings and facilitated interpretation of moderating factors from different perspectives, there was redundancy in some qualitative measures of fidelity. For example, interviews with TBI participants indicated issues (moderating factors) relating to how needs changed over time, which were also documented in the OT's clinical records. Trial OTs' frustrations in communicating with participants, were reported in both OT interviews and mentoring records. Given the resource implications of conducting, transcribing and analysing interviews, it could be argued that only using records of mentoring, may be more appropriate in a future trial (12).

The benchmark, which was derived from the description of the VR intervention delivered in an earlier study $(47,48)$, offered quality assurance that the FRESH intervention was delivered with fidelity despite anticipated variation in delivery. Variation was expected because of complexities associated with TBI, the intervention and work context, and the fact that the VR was delivered by different OTs in different sites. 
While some variation is concerned with improving the fit of the intervention (58-60), it may also be seen as non-adherence, negatively impacting on patient outcomes (61). Understanding variations in intervention implementation during trials and potential effects on patient outcomes is important (62). Using Stirman's (2013) system of coding variations to intervention delivery, the most frequently type observed in this study was 'tailoring'. Therefore, we explored both variation across and between OTs against the benchmark in terms of content and dose, which provided greater clarity about how OTs delivered VR. Trialists should examine this variation to understand implementation in real-world contexts and minimise dilution effects while achieving appropriate adaptation for local contexts (63). In this study, the range of fidelity measurement tools provided reassurance that variation was not nonadherence.

Some agreement is required as to what is an acceptable level of variation. The findings in this study suggest that variation of up to $15 \%$ in intervention component delivery across all therapists may be acceptable but variation in excess of this should be explored. Tailoring a complex intervention may result in variation and qualitative data should be able to explain this. Providing it remains below $40 \%$, this remains acceptable and consistent with others (52).

In this study the reported factors moderating intervention delivery provided important insights for future trials. They indicated in future there should be additional emphasis in training about the importance of completing intervention CRFs accurately along with practice sessions and emphasis on the importance of intervention dose. Changes in intervention CRFs should include clearer instructions for therapists to specifically record dates allow accurate reporting of starting and ending of the intervention and introduction of a new CRF to record planned versus actual attendance with reasons for non-attendance. Changes in the mentoring CRF should include clearer instructions for mentors to routinely discuss fidelity.

This study has indicated, which are the most useful methods for measuring fidelity in a future trial, so that we better understand why a complex intervention works or fails (23) and improve future trial designs (21). However, the intensity of data collection and the need for greater contextual understanding of the trial findings should be balanced with collecting only what is necessary for investigating the effectiveness of the intervention (12).

Although triangulation usefully revealed information about intervention complexity, missing data, the OTs' training needs and the measurement process, which is consistent with others' findings (44), this generated large volumes of data that required hours of analysis. In a future trial, measuring implementation fidelity in a proportion of trial therapists and using only the most useful measurement tools (fidelity checklist, intervention CRFs and mentoring records) is recommended.

Face-to-face fidelity monitoring visits were time consuming, but they were valuable (15). The researcher (JP) who assumed the dual role of trainer and mentor was an experienced OT and academic who enabled a professional relationship with the trial OTs. This permitted in-depth enquiry about fidelity, which may not have been possible with someone less experienced. In a future trial the responsibility of fidelity monitoring could be held by mentors and data verified by an independent researcher. 
Even though findings report on the experiences of only four OTs who implemented a new complex intervention and are unlikely to be representative of all therapists, they highlight important points for consideration when training OTs to deliver complex interventions and measuring their fidelity in a trial context.

\section{Conclusions}

OTs delivered the FRESH VR intervention with fidelity but also with variation, as expected and this was measured by data from multiple sources. This was useful in a feasibility trial because it identified factors likely to affect intervention fidelity in the future. However, multiple methods answer different questions. Fidelity checklists answer whether intervention processes were followed and explain the moderators. Adherence is answered with intervention CRFs and clinical records. Only expert mentoring provides realtime indicators to fidelity deviations and why. Mentoring facilitates fidelity and provides a window into trial processes if provided throughout intervention delivery. Focussing resources on providing mentoring to therapists delivering an intervention should be considered an important facilitatory tool for implementation fidelity that affords multiple benefits. Some methods do not add value to fidelity measurement and may be wasteful of resources. Qualitative interviews with OTs, participants, employers and NHS staff did not provide additional useful data for fidelity measurement.

When planning to assess fidelity as part of a feasibility trial, it is important to capture moderating factors to be able to account for possible threats to fidelity in a definitive trial and longer-term clinical implementation in the NHS.

\section{Abbreviations}

CFIF - The Conceptual Framework for Implementation Fidelity

CRF - case report form

DWP - Department for Work and Pensions

FRESH - Facilitating Return to work through Early Specialist Health-based interventions: feasibility randomised controlled trial

GCS - Glasgow coma scale

GP - General Practitioner

HCPC - Health and Care Professions Council

HTA - Health Technology Assessment

NHS - National Health Service 
NIHR - National Institute for Health Research

$\mathrm{OH}$ - Occupational Health

OT - Occupational Therapist

PwTBI - Person with a traumatic brain injury

REC - Research ethics committee

RCT - Randomised Controlled Trial

RTW - Return(ing) to work

$\mathrm{TBI}$ - traumatic brain injury

VR - vocational rehabilitation

\section{Declarations}

\section{Ethics approval and consent to participate}

Ethical approval was granted by the East Midlands Health Research Authority Research Ethics Service (REC Ref 13/EM/0353) 21 October 2013 and The University of Nottingham Ethics Committee (ref No. D14112013 FRESH SoM Rehab \& Ageing) 18 November 2013. The process for obtaining participant (patient and carer) informed consent was in accordance with Research Ethics Committee guidance, and Good Clinical Practice.

\section{Consent for publication}

Not applicable.

\section{Availability of data and materials}

The datasets used and/or analysed during the current study are available from the corresponding author on reasonable request.

\section{Competing interests}

Jain Holmes received consultancy fees as an employee of Obair Associates to train and mentor FRESH therapists and was subsequently granted PhD Studentship funding from the University of Nottingham and UK Occupational Therapy Research Foundation to work on this study. She was a paid employee of Obair Associates Ltd during the conduct of the study.

\section{Funding}


This research was funded by the National Institute for Health Research under the Health Technology Assessment (HTA) Programme (NIHR HTA programme grant no. 11/66/02).

\section{Authors' contributions -}

$\mathrm{JH}$ designed the fidelity study as part of her PhD programme of research with guidance and mentorship from KR who was Chief Investigator of the main FRESH trial and PhD supervisor to $\mathrm{JH}$. JH collected the data and completed the analyses with help from KR and JM. JH and JM wrote the first draft of the manuscript and JFS helped to further revise it in preparation for publication. All authors read and approved the final manuscript.

\section{Acknowledgements}

The authors would like to thank all the participants involved in the FRESH trial across the three sites and the OTs who delivered the intervention. The authors would also like to thank the FRESH study trial team for their support of this fidelity study, including the intervention trainers and mentors, Ruth Tyerman, Dr Julie Phillips, and Yash Bedekar. The expert service users who assisted in training the OTs, Jonathan Franchi, Trevor Jones and Stephanie Pravin. In addition, the authors would like to thank the NIHR for funding the FRESH trial. The first author also received funding from the UK Occupational Therapy Research Foundation and the University of Nottingham Doctoral Research Fellowship Grant through the Impact Campaign LifeCycle 3 and awarded by the UK Occupational Therapy Research Foundation.

\section{References}

1. Headway TB, Injury: H. 2020 [Available from: https://www.headway.org.uk/about-braininjury/individuals/types-of-brain-injury/traumatic-brain-injury/.

2. British Society of Rehabilitation Medicine. Rehabilitation after traumatic brain injury. A working party report of the British Society of Rehabilitation Medicine. London; 1998.

3. Parsonage M. Traumatic brain injury and offending: An economic analysis [Online]. Available at: https://www.centreformentalhealth.org.uk/traumatic-brain-injury [Accessed Accessed 29 May 2017]: Centre for Mental Health; 2016.

4. Simpson G, Tate R. Suicidality in people surviving a traumatic brain injury: prevalence, risk factors and implications for clinical management. Brain Inj. 2007;13-14(21):1335-51.

5. Berger E, Leven F, Pirente N, Bouillon B, Neugebauer E. Quality of Life after traumatic brain injury: A systematic review of the literature. Restor Neurol Neurosci. 1999;14:93-102.

6. Polinder S, Haagsma JA, van Klaveren D, Steyerberg EW, van Beeck EF. Health-related quality of life after TBI: a systematic review of study design, instruments, measurement properties, and outcome. Population health metrics. 2015;13:4-.

7. Cancelliere C, Kristman VL, Cassidy JD, Hincapie CA, Cote P, Boyle E, et al. Systematic review of return to work after mild traumatic brain injury: results of the International Collaboration on Mild Traumatic 
Brain Injury Prognosis. Arch Phys Med Rehabil. 2014;95(3 Suppl):201-9.

8. Materne M, Lundqvist LO, Strandberg T. Opportunities and barriers for successful return to work after acquired brain injury: A patient perspective. Work. 2017;56:125-34.

9. Saltychev M, Eskola M, Tenovuo O, Laimi K. Return to work after traumatic brain injury: Systematic review. Brain injury: [BI]. 2013;27(13-14):1516-27.

10. Playford E, Radford K, Burton C, Gibson A, Jellie B, Sweetland J, et al. Mapping vocational rehabilitation services for people with long term neurological conditions: summary report. London: Department of Health; 2011.

11. Radford K, Sutton C, Sach T, Holmes J, Watkins C, Forshaw D, et al. Early, specialist vocational rehabilitation to facilitate return to work after traumatic brain injury: the FRESH feasibility RCT. Health Technol Assess. 2018;22(33):1-124.

12. Toomey E, Hardeman W, Hankonen N, Byrne M, McSharry J, Matvienko-Sikar K, et al. Focusing on fidelity: narrative review and recommendations for improving intervention fidelity within trials of health behaviour change interventions. Health Psychology Behavioral Medicine. 2020;8(1):132-51.

13. Hankonen N, Heino MTJ, Hynynen S-T, Laine H, Araújo-Soares V, Sniehotta FF, et al. Randomised controlled feasibility study of a school-based multi-level intervention to increase physical activity and decrease sedentary behaviour among vocational school students. International Journal of Behavioral Nutrition Physical Activity. 2017;14(1):37.

14. Chesworth BM, Leathley MJ, Thomas LH, Sutton CJ, Forshaw D, Watkins CL. Assessing fidelity to treatment delivery in the ICONS (Identifying Continence OptioNs after Stroke) cluster randomised feasibility trial. BMC Med Res Methodol. 2015;15(1):1-9.

15. Feely M, Seay KD, Lanier P, Auslander W, Kohl PL. Measuring Fidelity in Research Studies: A Field Guide to Developing a Comprehensive Fidelity Measurement System. Child Adolesc Soc Work J. 2018;35(2):139-52.

16. MacEachen E, Clarke J, Franche R-L, Irvin E. Workplace-based Return to Work Literature Review G. Systematic review of the qualitative literature on return to work after injury. Scand J Work Environ Health. 2006;32(4):257-69.

17. Walton H, Tombor I, Burgess J, Groarke H, Swinson T, Wenborn J, et al. Measuring fidelity of delivery of the Community Occupational Therapy in Dementia-UK intervention. BMC Geriatrics. 2019;19(1):364.

18. Dopp CME, Graff MJL, Teerenstra S, Adang E, Nijhuis-van der Sanden RWG, OldeRikkert MGM, Vernooij-Dassen $\mathrm{M}$. A new combined strategy to implement a community occupational therapy intervention: designing a cluster randomized controlled trial. Bmc Geriatrics. 2011;11.

19. Bosch M, van der Weijden T, Wensing M, Grol R. Tailoring quality improvement interventions to identified barriers: a multiple case analysis. J Eval Clin Pract. 2007;13:1356-294.

20. Colditz GA. The promise and challenges of dissemination and implementation research. In: Brownson RC, Colditz GA, Proctor EK, editors. Dissemination and implementation research in health: translating science to practice: Oxford University Press; 2012. 
21. Allen JD, Linnan LA, Emmons KM Fidelity and its relationship to implementation effectiveness, adaptation, and dissemination. In: Brownson RC, Colditz GA, Proctor EK, editors. Dissemination and implementation research in health: translating science to practice: Oxford University Press; 2012.

22. Hamilton A, Mittman BS,. Implementation science in healthcare. In: Brownson RC, Colditz, G.A., Proctor, E.K.,, editor. Dissemination and implementation research in health: translating science to practice: Oxford University Press; 2012.

23. Walker MF, Hoffmann TC, Brady MC, Dean CM, Eng JJ, Farrin AJ, et al. Improving the development, monitoring and reporting of stroke rehabilitation research: Consensus-based core recommendations from the Stroke Recovery and Rehabilitation Roundtable. International Journal of Stroke. 2017;12(5):472-9.

24. Dusenbury L, Brannigan R, Falco M, Hansen WB. A review of research on fidelity of implementation: implications for drug abuse prevention in school settings. Health Educ Res. 2003;18(2):237-56.

25. Holmes J, Phillips J, Morris R, Bedekar Y, Tyerman R, Radford K. Development and evaluation of an early specialised traumatic brain injury vocational rehabilitation training package. British Journal of Occupational Therapy. 2016;79(11):693-702.

26. Holmes JA. Implementing complex rehabilitation interventions in research: the example of vocational rehabilitation for people with traumatic brain injury: University of Nottingham; 2018.

27. Bellg A, Borrelli B, Resnick B, Hecht J, Minicucci D, Ory M, Ogedegbe G, Orwig D, Ernst D, Czajkowski $\mathrm{S}$. Enhancing treatment fidelity in health behaviour change studies: Best practices and recommendations from the NIH Behavior Change Consortium. Health Psychol. 2004;23:443-51.

28. Craig P, Dieppe P, Macintyre S, Michie S, Nazareth I, Petticrew M. Developing and evaluating complex interventions: the new Medical Research Council guidance. BMJ. 2008;337:a1655.

29. Hildebrand MW, Host HH, Binder EF, Carpenter B, Freedland KE, Morrow-Howell N, et al. Measuring Treatment Fidelity in a Rehabilitation Intervention Study. Am J Phys Med Rehabil/Assoc Acad Physiatr. 2012;91(8):715-24.

30. Carroll C, Patterson M, Wood S, Booth A, Rick J, Balain S. A conceptual framework for implementation fidelity. Implementation science: IS. 2007;2:40.

31. Connell LA, McMahon NE, Harris JE, Watkins CL, Eng JJ. A formative evaluation of the implementation of an upper limb stroke rehabilitation intervention in clinical practice: a qualitative interview study. Implementation science: IS. 2014;9:90-

32. Masterson-Algar P, Burton CR, Rycroft-Malone J, Sackley CM, Walker MF. Towards a programme theory for fidelity in the evaluation of complex interventions. J Eval Clin Pract. 2014;20(4):445-52.

33. Borrelli B, Sepinwall D, Ernst D, Bellg AJ, Czajkowski S, Breger R, DeFrancesco C, Levesque C, Sharp DL, Ogedegbe G, Resnick B, Orwig D. A new tool to assess treatment fidelity and evaluation of treatment fidelity across 10 years of health behavior research. J Consult Clin Psychol. 2005;73(5):852-60.

34. Brandt PA, Kirsch SD, Lewis FM, Casey S. Assessing the strength and integrity of an intervention. Oncol Nurs Forum. 2004;31(4):833-7. 
35. Fixsen DL, Naoom SF, Blase KA, Friedman RM, Wallace F,. Implementation research: A synthesis of the literature. Tampa, FL: University of South Florida, Louis de la Parte Florida Mental Health Institute, The National Implementation Research Network (FMHI Publication 231); 2005 2005//.

36. Forgatch M, Patterson G, DeGarmo D. Evaluating Fidelity: Predictive Validity for a Measure of Competent Adherence to the Oregon Model of Parent Management Training. Behav Ther. 2005;36:313.

37. Hennessey ML, Rumrill PD Jr. Treatment fidelity in rehabilitation research. J Vocat Rehabil. 2003;19:123-6.

38. Moncher FJ, Prinz RJ. Treatment fidelity in outcome studies. Clin Psychol Rev. 1991;11(3):247-66.

39. Perrin KM, Burke SG, O'Connor D, Walby G, Shippey C, Pitt S, McDermott RJ, Forthofer MS,. Factors contributing to intervention fidelity in a multi-site chronic disease self-management program. Implementation Science. 2006;1.

40. Toomey E, Matthews J, Hurley DA. Using mixed methods to assess fidelity of delivery and its influencing factors in a complex self-management intervention for people with osteoarthritis and low back pain. BMJ open. 2017;7(8):e015452.

41. Hasson H. Systematic evaluation of implementation fidelity of complex interventions in health and social care. Implementation Science. 2010;5(1):1-9.

42. Walton $\mathrm{H}$, Spector A, Williamson M, Tombor I, Michie S. Developing quality fidelity and engagement measures for complex health interventions. Br J Health Psychol. 2020;25(1):39-60.

43. Williams SL, McSharry J, Taylor C, Dale J, Michie S, French DP. Translating a walking intervention for health professional delivery within primary care: A mixed-methods treatment fidelity assessment. $\mathrm{Br}$ J Health Psychol. 2020;25(1):17-38.

44. Hasson H, Blomberg S, Dunér A. Fidelity and moderating factors in complex interventions: a case study of a continuum of care program for frail elderly people in health and social care. Implementation Science. 2012;7(1):1-11.

45. Siemonsma P, Dopp C, Alpay L, Tak E, van Meeteren N, Chorus A. Determinants influencing the implementation of home-based stroke rehabilitation: a systematic review. Disabil Rehabil. 2014;36(24):2019-30.

46. Radford K, Phillips J, Jones T, Gibson A, Sutton C, Watkins C, et al. Facilitating return to work through early specialist health-based interventions (FRESH): protocol for a feasibility randomised controlled trial. Pilot Feasibility Studies. 2015;1(1):24.

47. Phillips J. Return to work after traumatic brain injury: a cohort comparison study and feasibility economic analysis: University of Nottingham; 2013.

48. Phillips J, Drummond A, Radford K, Tyerman A. Return to work after traumatic brain injury: recording, measuring and describing occupational therapy intervention. Br J Occup Ther. 2010;73(9):422-30.

49. Radford K, Phillips J, Drummond A, Sach T, Walker M, Tyerman A. Return to work after traumatic brain injury: cohort comparison and economic evaluation. Brain injury: [BI]. 2013;27(5):507-20. 
50. Vadivale M. ICH-GCP Guidelines for Clinical Trials. Berita MMA. 1999;7(29).

51. Damschroder LJ, Goodrich DE, Kim HM, Holleman R, Gillon L, Kirsh S, et al. Development and validation of the ASPIRE-VA coaching fidelity checklist (ACFC): a tool to help ensure delivery of highquality weight management interventions. Translational behavioral medicine. 2016;6(3):369-85.

52. Durlak JA, DuPre EP. Implementation Matters: A Review of Research on the Influence of Implementation on Program Outcomes and the Factors Affecting Implementation. Am J Community Psychol. 2008;41(3-4):327-50.

53. Gale NK, Heath G, Cameron E, Rashid S, Redwood S. Using the framework method for the analysis of qualitative data in multi-disciplinary health research. BMC Med Res Methodol. 2013;13(1):117.

54. Teasdale G, Maas A, Lecky F, Manley G, Stocchetti N, Murray G. The Glasgow Coma Scale at 40 years: standing the test of time. Lancet Neurol. 2014;13(8):844-54.

55. O'Cathain A, Murphy E, Nicholl J. Three techniques for integrating data in mixed methods studies. BMJ. 2010;341:c4587.

56. Sambunjak D, Straus SE, Marušić A. Mentoring in academic medicine: a systematic review. JAMA. 2006;296(9):1103-15.

57. Abdullah G, Rossy D, Ploeg J, Davies B, Higuchi K, Sikora L, et al. Measuring the effectiveness of mentoring as a knowledge translation intervention for implementing empirical evidence: a systematic review. Worldviews Evid Based Nurs. 2014;11(5):284-300.

58. Damschroder LJ, Aron DC, Keith RE, Kirsh SR, Alexander JA, Lowery JC. Fostering implementation of health services research findings into practice: a consolidated framework for advancing implementation science. Implementation science: IS. 2009;4:50.

59. Hawe P, Shiell A, Riley T, Gold L. Methods for exploring implementation variation and local context within a cluster randomised community intervention trial. J Epidemiol Community Health. 2004;58:788-93.

60. Moore GF, Audrey S, Barker M. Process evaluation of complex interventions: Medical Research Council guidance. BMJ. 2015;350:h1258.

61. Mihalic S. The importance of implementation fidelity. Emotional Behavioral Disorders in Youth. 2004;4:83-6.

62. Stirman SW, Miller CJ, Toder K, Calloway A. Development of a framework and coding system for modifications and adaptations of evidence-based interventions. Implementation Science. 2013;8(1):65.

63. McCrabb S, Lane C, Hall A, Milat A, Bauman A, Sutherland R, et al. Scaling-up evidence-based obesity interventions: A systematic review assessing intervention adaptations and effectiveness and quantifying the scale-up penalty. Obes Rev. 2019;20(7):964-82.

\section{Figures}




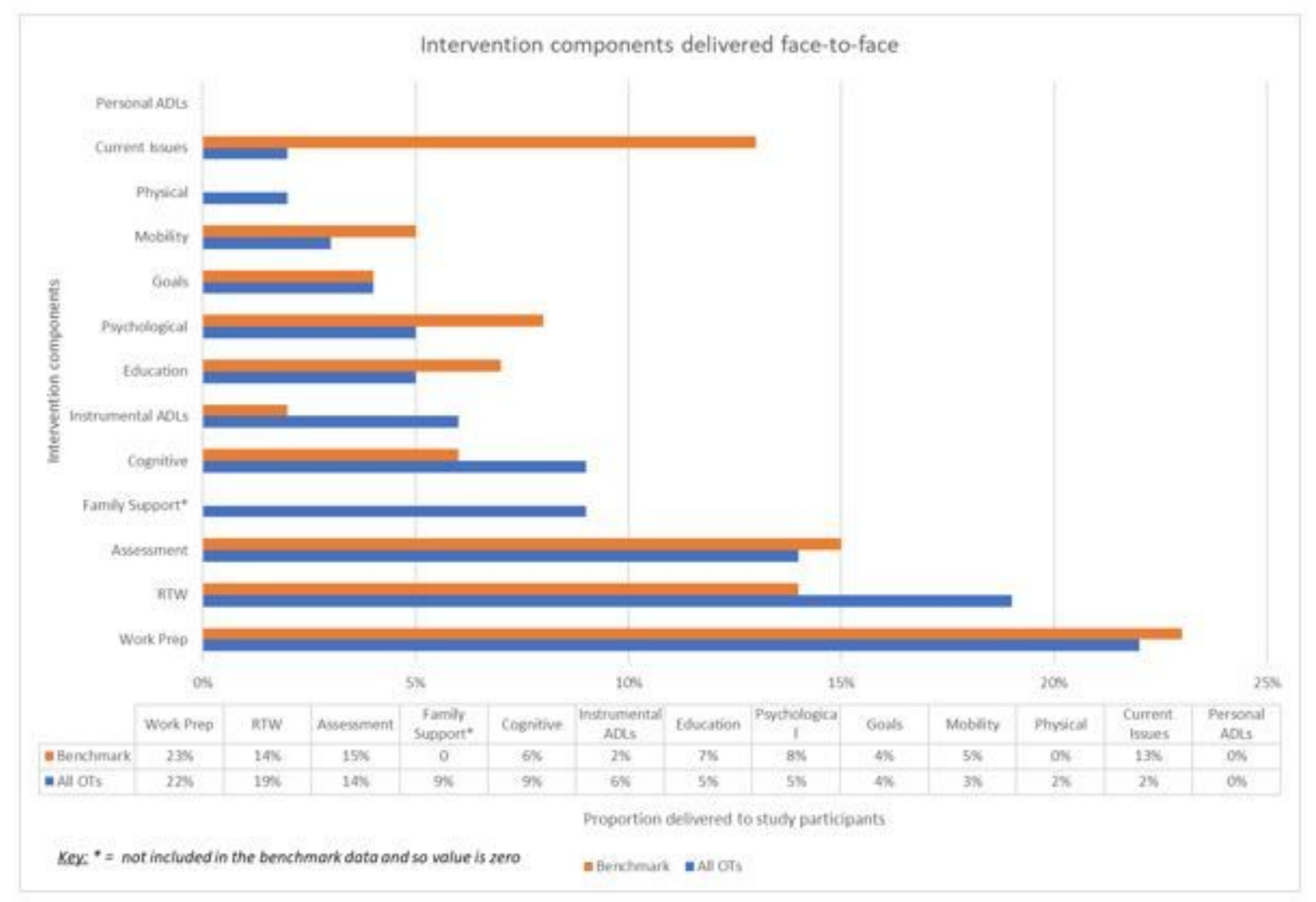

Figure 1

Comparison of all OTs and Benchmark delivery of intervention components

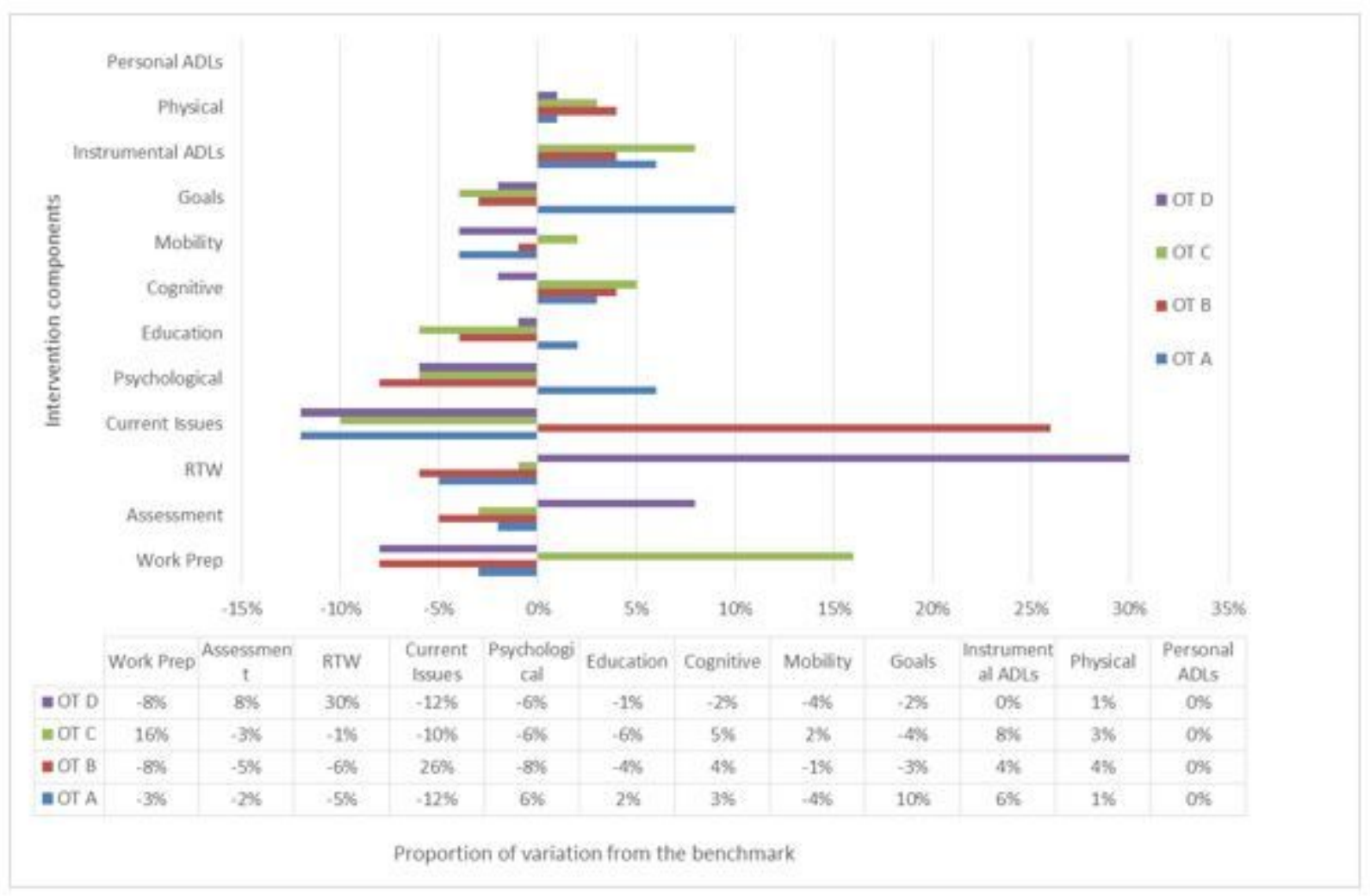

Figure 2 
Individual OT variation in delivery of components compared to the benchmark

\section{Supplementary Files}

This is a list of supplementary files associated with this preprint. Click to download.

- AdditionalFile2DescriptionofFRESHVR.docx

- AdditionalFile4Fidelityvisitchecklist.docx

- Additionalfile3FRESHVRLogicModel.docx

- AdditionalFIle1FlowdiagramFRESHProcessEvaluation.docx 